\title{
The female genitalia of the genus Zabrus (Coleoptera: Carabidae: Zabrini). I. The general structure and the subgenera Zabrus, Euryzabrus, Platyzabrus and Epomidozabrus.
}

\author{
VicenTE M. ORTUÑO, José SERRANO, ANTONIO ANDÚJAR and José L. LENCINA
}

Departamento de Zoología, Facultad de Veterinaria, Universidad de Murcia. Campus de Espinardo. Aptdo. 4021.30071 Murcia, Spain; e-mail: jserrano@um.es

Key words. Female genitalia, Zabrus, Carabidae, Coleoptera

\begin{abstract}
The systematics of the genus Zabrus Clairville, 1806 is currently based on morphological characters that show a high degree of parallelism. The aim of this study is to find new characters in the female genitalia, which give a better understanding of the phylogeny of the genus and result in a new classification based on monophyletic taxa (subgenera and species groups). For this purpose slides of the whole female reproductive tract were studied under light microscopy and the gonocoxa IX under scanming microscopy. The study of species belonging to eight subgenera of Zabrus, and of twelve subgenera of its sister taxon Amara, shows that Zabrus is characterised by the lack of a spermatheca. This apomorphy is reported for the first time in carabids, and corroborates the monophyly of the genus in comparison to Amara. A villous canal that is intimately joined to the distal bursa copulatrix was found in both genera and in species of related tribes. This feature could be an apomorphy of the Harpalidae sensu Deuve (1988). However, only in Zabrus does the villous canal end in a long falciform head, which is probably another autapomorphy of the genus. It is postulated that the primitive bursa copulatrix of the genus was made up of a moderately inflated basal half and an elongated and simple distal half. This pattern is found in species of the subgenus Zabrus, which are widely distributed, and the subgenera Euryzabrus, Platyzabrus, and Epomidozabrus, which are endemic to the Iberian Peninsula. Extra lobules arising in the region where the two parts of the bursa meet, and cup-like infoldings of the distal bursa are possible apomorphic states that characterise the subgenera Pelor and Iberozabrus. Gonocoxite 2 does not have the strong and short spines found in species of related taxa. Differences in size and shape of both gonocoxites, distribution of setation and microtrichia, and presence of furrow "pegs" are characters of potential phylogenetic interest, which should be thoroughly investigated in other subgenera.
\end{abstract}

\section{INTRODUCTION}

The genus Zabrus Clairville, 1806 is included in the subfamily Pterostichinae and the tribe Zabrini, and comprises about 105 species mostly distributed in the Mediterranean Basin. The current classification of the subgenera is mainly based on external characters of the adult and the geographic distribution of taxa (Ganglbauer, 1915). Most of these subgenera are endemic to particular areas and are probably monophyletic groups, which may be characterised by one or more apomorphies. However, the large subgenus Pelor Bonelli, 1810 is a polyphyletic assemblage of more than 60 species, a major systematic problem that remains to be solved. Freude (1986, 1988, $1989,1990)$ revised the genus Zabrus but used the same criteria as Ganglbauer, which contributed little to a better understanding of the nature of the species groups proposed by Ganglbauer (1915) for Pelor. The subgenus Iberozabrus Ganglbauer, 1915 with 22 species also presents many taxonomic difficulties (Andújar \& Serrano, 2001). As noted by these authors parallel evolutionary changes in external morphology are common among and within the subgenera of Zabrus, thus giving rise to homoplasies that make it difficult to analyse phylogenetic relationships. Characters other than those found in the external morphology of the imago are needed for assessing the phylogenetic relationships between the sub- genera and establishing a new taxonomy based on these relationships.

The female genitalia of Zabrus are a possible source of taxonomic and phylogenetic characters (e.g., Holdhaus 1912; Liebherr \& Will 1998; Ortuño 1994, 1998; Ortuño et al. 1992), which have not been adequately investigated. To date only Schuler (1968) has reported a few observations on $Z$. tenebrioides (Goeze, 1777) and $Z$. obesus Audinet-Serville, 1821. We have started a detailed analysis of the female genitalia of Zabrus, looking for characters that could have a phylogenetic and a taxonomic value. In this paper we aimed to establish a general pattern for the genus and to study all species included in the nominal subgenus and three subgenera endemic to the Iberian Peninsula. We also studied species belonging to the genus Amara Bonelli 1810, the sister taxon of Zabrus, to help with the phylogenetic analysis.

\section{MATERIAL AND METHODS}

The species studied belong to the following subgenera:

Subgenus Zabrus. Zabrus ignavus Csiki, 1907; Z. morio Ménétriès, 1832; Z. tenebrioides (Goeze, 1777).

Subgenus Epomidozabrus Ganglbauer, 1915. Zabrus flavangulus Chevrolat, $1840 ; Z$. humeralis Uhagón, 1904; Z. mateui Novoa, 1980.

Subgenus Euryzabrus Ganglbauer, 1915. Zabrus pinguis Dejean, 1831. 

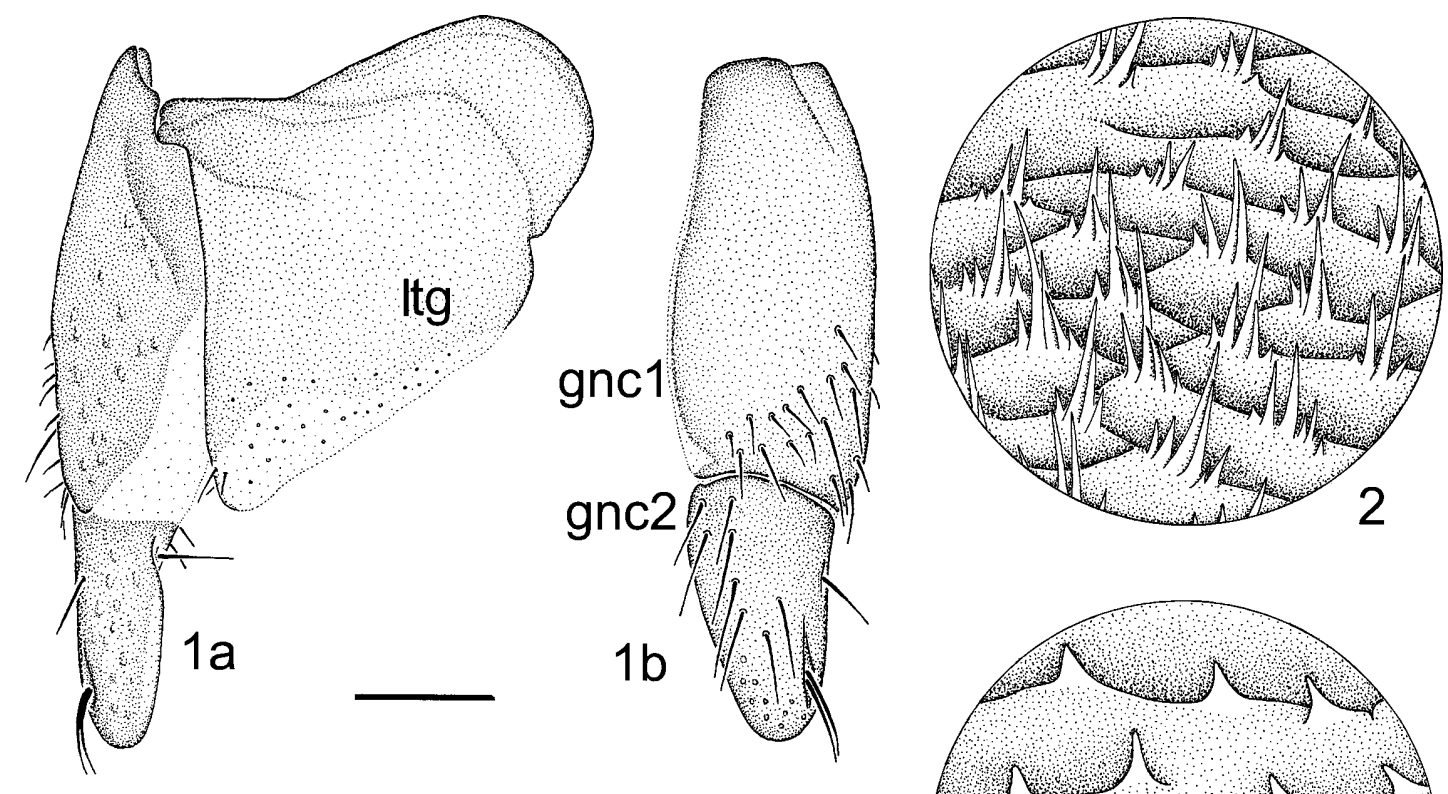

Fig. 1. Gonocoxa IX of female Zabrus. Z. gravis, gonocoxa with laterotergite (ltg) in ventrolateral view (1a) and ventral view (1b), showing the proximal (gnc 1) and the distal (gnc 2) gonocoxites separated by an articulating membrane.

Figs. 2-3. Microtrichia on the articulating membrane between gonocoxites 1 and 2 of Zabrus. $2-Z$. mateui, microtrichia forming groups; $3-Z$. pecoudi, isolated microtrichia. The bar equals $0.33 \mathrm{~mm}$ in Fig. 1 and $7.4 \mu \mathrm{m}$ in Figs $2-3$.

Subgenus Platyzabrus Jeanne, 1968. Zabrus constrictus Graells, 1858; Z. pecoudi Colas, 1942.

To establish the general pattern of the female genitalia in Zabrus we also studied species of other subgenera:

Subgenus Iberozabrus Ganglbauer, 1915. Z. angustatus Rambur, 1838; Z. castroi Martínez, 1873; Z. coiffaiti Jeanne, 1970; $Z$. curtus curtus Audinet-Serville, 1821; Z. consanguineus Chevrolat, 1865 ; Z. gravis Dejean, 1828 ; Z. seidlitzi seidlitzi Schaum, 1864

Subgenus Macarozabrus Ganglbauer, 1915. Zabrus crassus Dejean, 1828; Z. laevigatus Zimmermann, 1831.

Subgenus Pelobatus Fischer von Waldheim, 1817. Zabrus aciculatus Schaum, 1864; Z. aurichalceus Adams, 1817.

Subgenus Pelor Bonelli, 1810. Z. balcanicus Heyden, 1883; Z. corpulentus Schaum, 1864; Z. damascenus Reiche et Saulcy, 1855; Z. femoratus Dejean, 1828; Z. graecus Dejean, 1828; Z. iconiensis Ganglbauer, 1905; Z. melancholicus Schaum, 1864; Z. peristericus Apfelbeck, 1904; Z. punctiventris Schaum, 1864; Z. reflexus Schaum, 1862; Z. rhodopensis Apfelbeck, 1904; $Z$. robustus Zimmermann, 1831; Z. rotundicollis Ménétriès, 1836; Z. spinipes (Fabricius, 1798); Z. trinii Fischer von Waldheim, 1817.

For comparisons with the sister taxon of Zabrus, the genus Amara Bonelli, 1810, we studied species of the subgenera Amara, Zezea Csiki, 1929, Celia Zimmermann, 1831, Camptocelia Jeannel, 1942, Paracelia Bedel, 1899, Leiocnemis Zimmermann, 1831, Amathitis Zimmermann, 1831, Percosia Zimmermann, 1831, Bradytus Stephens, 1828, Leironotus Ganglbauer, 1892, Acorius Zimmermann, 1831 and Curtonotus Stephens, 1828.

The beetles used in this study are deposited in the Museo Nacional de Ciencias Naturales de Madrid, the Departamento de Zoología de la Universidad de Murcia, the Institut Royal des Sciences Naturelles de Belgique, the Naturhistorisches Museum Wien, and the private collection of J. Vives (Barcelona), J.P. Zaballos (Madrid), F. Prieto (Madrid) and J.L. Lencina (Jumilla, Murcia). Slides with dissections of female genitalia and mounted pieces for scanning microscopy are deposited in Departamento de Zoología de la Universidad de Murcia.

The last abdominal segments of the female were gently squeezed with the forceps and introduced in an aqueous saturated solution of $\mathrm{KOH}$ for $24-48 \mathrm{~h}$. Then they were washed in Scheerpeltz's solution, opened dorsally to check alkaline digestion, and stained with Chlorazol black $E \circledR$ in aqueous solution for 1-3 min under visual control. The excess of dye was removed by washing in hot $\mathrm{KOH}$ and the structures washed again in Scheerpeltz's solution. The dissected structures were placed in a watchglass with Scheerpeltz's solution and observed and drawn using a ZEISS stereomicroscope. Permanent slide mounts were made of selected dissections. A routine procedure was followed in preparing the female reproductive appendages for scanning microscopy. Observations and photographs were made using a JEOL JSM-6100.

\section{RESULTS}

\section{The general structure of the female genitalia of Zabrus}

The gonocoxa IX is well sclerotised and separated medially by a membranous articulation into gonocoxite 1 and gonocoxite 2 (Fig. 1). This last segment has on the ventral surface a subapical groove with two large sensorial setae (Fig. 7) and 1-3 short sensorial setae (Fig. 4; 

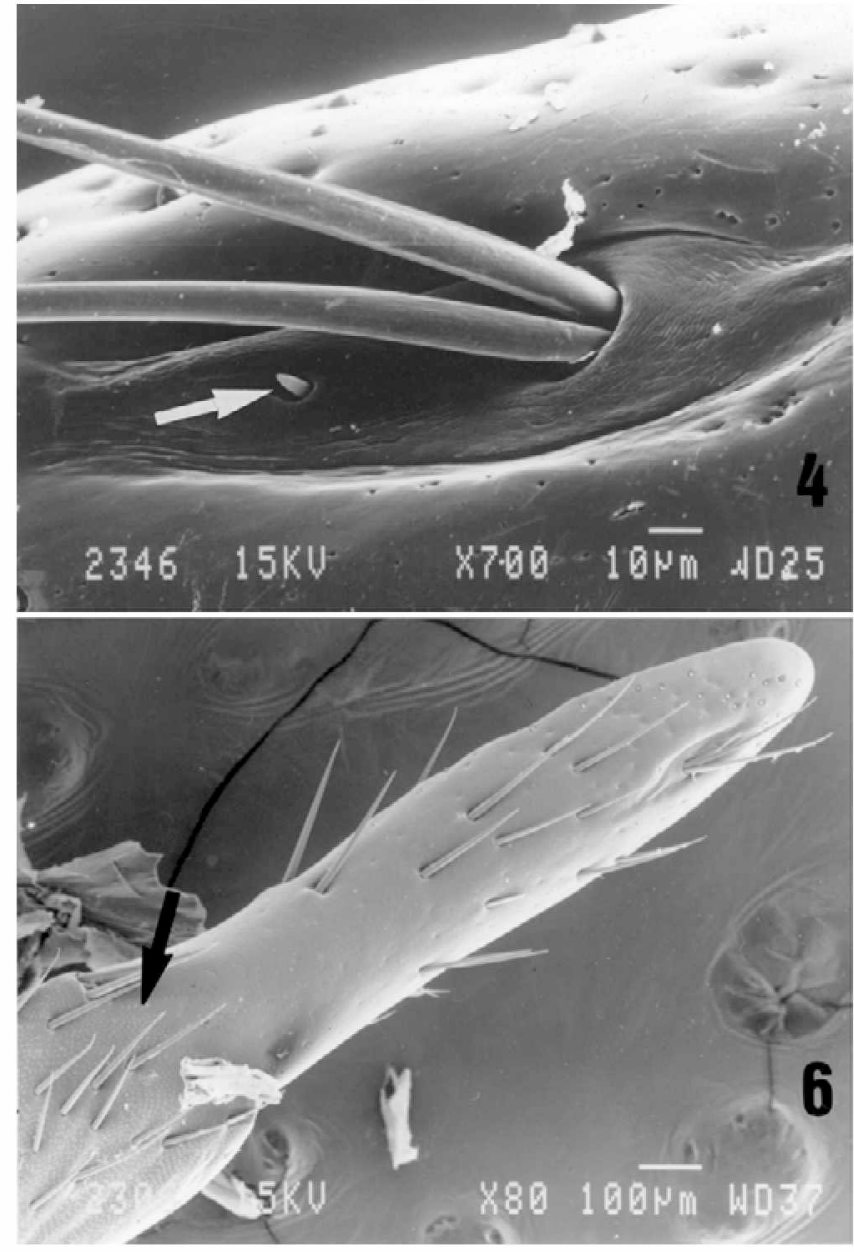

6

"furrow pegs" sensu Liebherr, 1989a, b), and some additional setae of varying size scattered over the segment (Figs 1b, 7). The dorsal surface has one conspicuous seta on each side of the basal half of the segment, but the strong and lateral spines we found in most of the species of Amara are absent. In some species there are additional setae dispersed over gonocoxite 2 (Fig. 5).

Gonocoxite 1 is more elongate and parallel sided (Fig. 1). On the ventral surface there are many setae, usually arranged in a triangular field close to the articulating membrane with gonocoxite 2 , and many evenly distributed small setae (microtrichia). In some species this segment is ventrally grooved. In SEM images there are microtrichia grouped in sets of 2-6 small spines on the articulating membrane of both segments (Fig. 2); in the subgenus Platyzabrus these microtrichia are single toothed (Fig. 3).

The laterotergite IX is triangular in shape, weakly sclerotised and almost devoid of setae (Fig. 1a).

The basal half of the bursa copulatrix is usually inflated. It is joined to the distal tubular part via an invaginated area, where some additional lobules may be found (Figs 14, 17). The excretory duct of the single spermathecal gland opens where the two regions of the bursa meet (Fig. 8). The distal bursa is more or less elongated and may show a variable number of cup-like infoldings (Figs 9, 19). A villous canal arises at the beginning of the

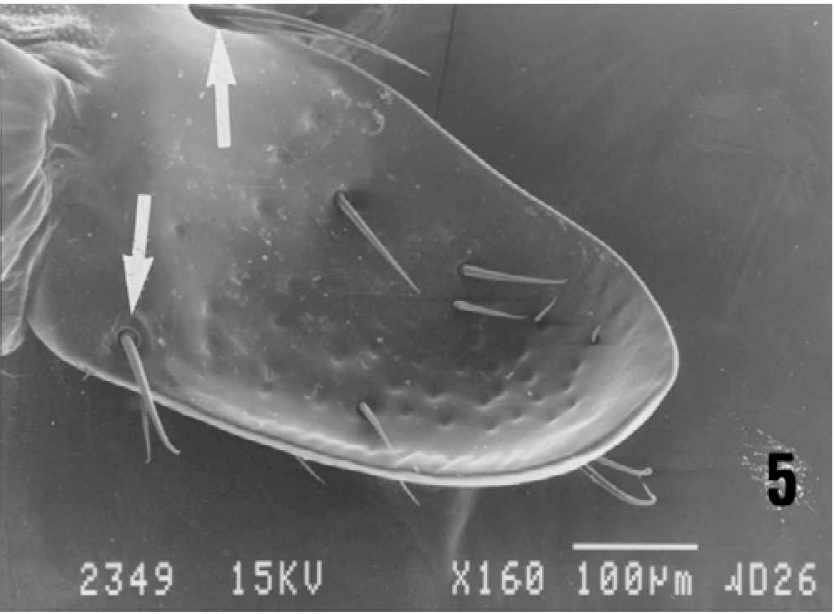

Figs. 4-6. SEM images of female Zabrus gonocoxae IX. 3. 4 $-Z$. pinguis, subapical groove of gonocoxite 2 in ventral view showing one furrow "peg" (arrow); $5-Z$. mateui, gonocoxite 2 in dorsal view showing one large lateral setae on each side (arrows); $6-Z$. pinguis, note the lack of articulating membrane between gonocoxites (arrow). The bar equals $10 \mu \mathrm{m}$ in Fig. 4 , $100 \mu \mathrm{m}$ in Fig. 5 and $100 \mu \mathrm{m}$ in Fig. 6.

distal bursa and extends towards the common oviduct (Fig. 8). This canal ends in a well-developed glandular falciform head, in the region where the bursa and the common oviduct meet (Figs 8-19). The villous canal is also found in related species of Amara but lacks the falciform head. Species of other tribes also have this canal, which only becomes apparent after prolonged staining with Chlorazol black ${ }^{\circledR}$ (data not shown).

The most distinctive feature of the genus is the lack of a spermatheca, a structure that is present in species of Amara and other more distantly related taxa of the tribes Pterostichini, Platynini and Sphodrini.

\section{The subgenus Zabrus}

Gonocoxite 2 is short and has a rounded apex. The ventral groove has one to three furrow pegs. Gonocoxite 1 is ventrally grooved in $Z$. ignavus, and smooth in $Z$. tenebrioides and $Z$. morio. The bursa copulatrix in the three species of this subgenus has a relatively simple tubular region, which is very long in $Z$. ignavus (Fig. 10), short in Z. morio (Fig. 8), and with three rudimentary infoldings in Z. tenebrioides (Fig. 9).

\section{The subgenus Euryzabrus}

Both gonocoxites are elongate and of about the same length, gonocoxite 2 has a large number of setae on the ventral surface and an unusual row of setae on each margin of the dorsal surface. The articulating membrane 

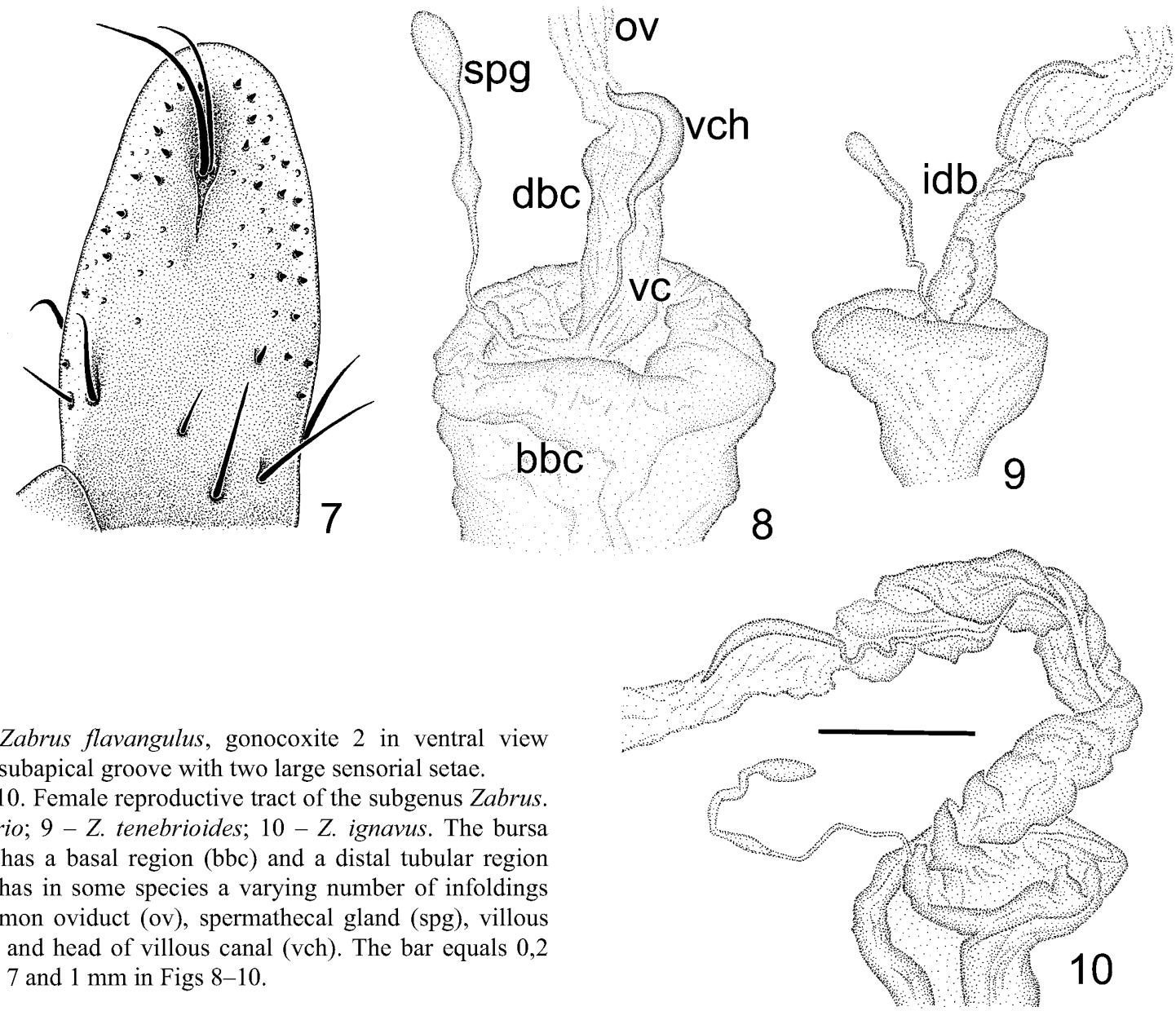

Fig. 7. Zabrus flavangulus, gonocoxite 2 in ventral view showing a subapical groove with two large sensorial setae.

Figs 8-10. Female reproductive tract of the subgenus Zabrus. $8-Z$. morio; $9-Z$. tenebrioides; $10-Z$. ignavus. The bursa copulatrix has a basal region (bbc) and a distal tubular region $(\mathrm{dbc})$ that has in some species a varying number of infoldings (idb); common oviduct (ov), spermathecal gland (spg), villous canal (vc), and head of villous canal (vch). The bar equals 0,2 $\mathrm{mm}$ in Fig. 7 and $1 \mathrm{~mm}$ in Figs $8-10$.

between these gonocoxites varies from complete to partially incomplete (Fig. 6). The bursa copulatrix is among the simplest in the genus, with a short tubular region. The villous canal has a long glandular head (Fig. 11).

\section{The subgenus Platyzabrus}

Gonocoxite 2 is relatively long and may have up to 10 setae. The tubular part of the bursa lacks the infoldings seen in other species but is somewhat dilated close to the junction with the common oviduct. The basal half of the bursa has two clear infoldings (Figs 12, 13).

\section{The subgenus Epomidozabrus}

Gonocoxite 2 is relatively short (slender in Z. mateui) and has a deep apical groove without furrow pegs in $Z$. flavangulus. This needs to be confirmed by studying more individuals. The dorsal surface of this gonocoxite has a few setae in $Z$. mateui. Gonocoxite 1 has a welldeveloped field of setae close to the articulating membrane between the gonocoxites. It is clearly grooved in $Z$. mateui, and almost smooth in Z. humeralis and Z. flavangulus. The tubular part of the bursa is relatively simple, without clear infoldings. An extra lobule arises where the two parts of the bursa met in Z. flavangulus (Fig. 14) and (to a lesser extent) Z. humeralis (Fig. 15), but is almost wanting in Z. mateui (Fig. 16).

\section{Other subgenera of Zabrus}

The species of other subgenera usually have an inflated basal portion to the bursa copulatrix (Figs 17-19), followed by an elongated distal part with a variable number of infoldings. In the case of $Z$. (Pelor) corpulentus, there are 7-8 of these cup-like infoldings (Fig. 19). In the subgenus Iberozabrus there may be additional features such as some extra lobules arising from the region where the two parts of the bursa meet (Z. seidlitzi, Fig. 17).

\section{DISCUSSION}

The general structure of the female genitalia in Zabrus

The most remarkable feature of the genus is the lack of a spermatheca, an organ that is present in all the carabids studied to date. Only in Loxandrus celeris (Dejean, 1828) (tribe Loxandrini) is the spermatheca markedly reduced (Liebherr \& Will 1998). The presence of the spermatheca in species of the closely related genus Amara was shown by Ali (1967) and corroborated by this study. Schuler (1968) described a spermatheca in Zabrus tenebrioides, but his drawings indicate he is referring to the villous canal and its falciform head. In the case of $Z$. (Pelor) obesus he correctly noted the lack of a spermatheca. This character state is thus considered an autapomorphy indicating the monophyly of the genus. Freude (1986) questioned the separation of Zabrus from its sister taxon, the genus Amara, because some species of the latter show 

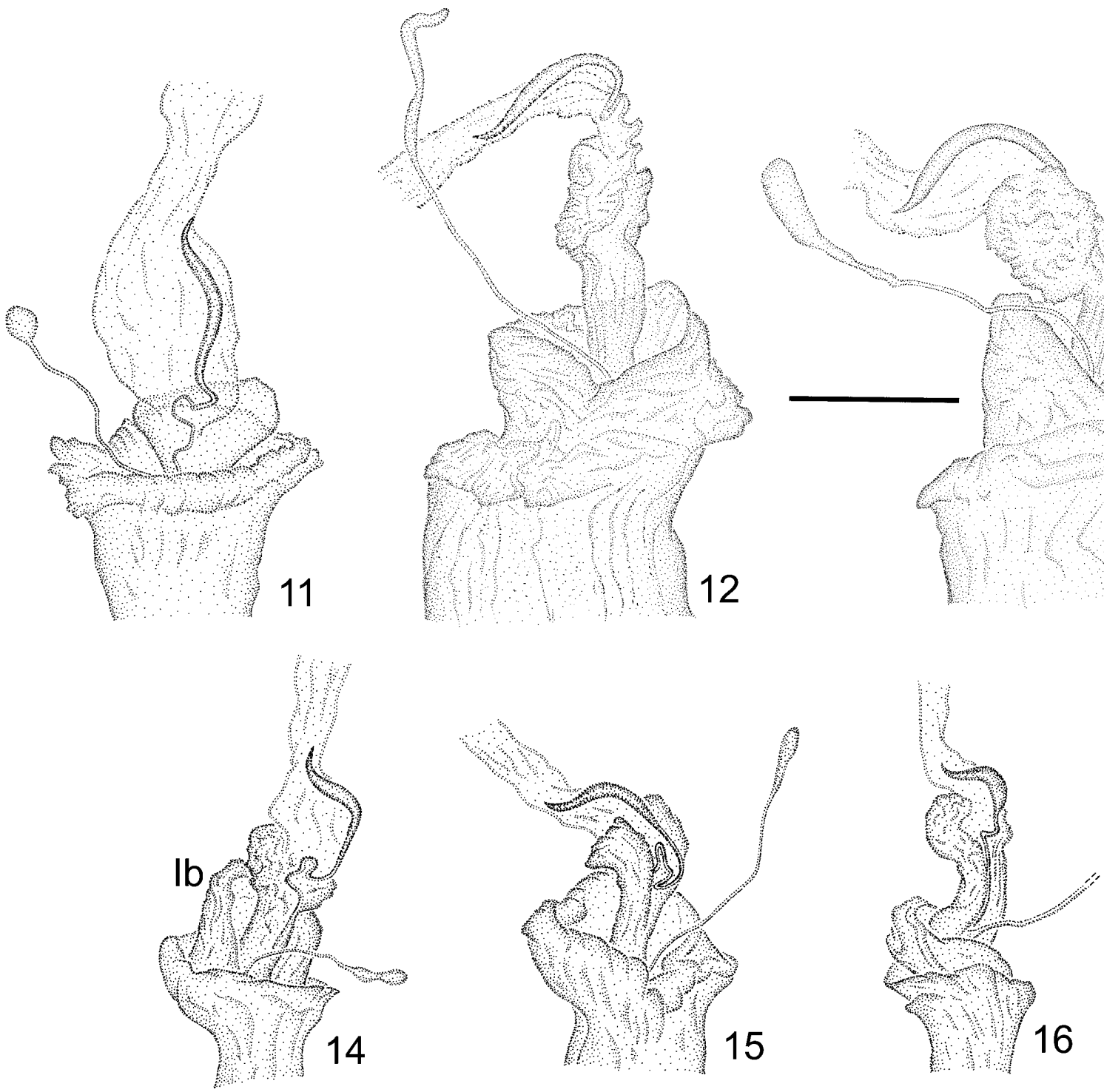

Figs 11-16. Female reproductive tract of the subgenera Euryzabrus $(11-Z$. pinguis $)$, Platyzabrus $(12-Z$. constrictus; $13-Z$. pecoudi) and Epomidozabrus (14 - Z. flavangulus; $15-$ Z. humeralis; $16-$ Z. mateui). The bar equals $1 \mathrm{~mm}$.

one or two of the diagnostic traits of a typical adult Zabrus (e.g., the single periorbital seta found in A. (Polysitamara) luppovae Kryzhanovskij, 1962). However, the lack of a spermatheca plus the high chromosome number and some larval characters of Zabrus (Andújar \& Serrano, 2000) support the monophyly of Zabrus.

Both Zabrus and Amara have a villous canal similar to that described for the tribes Licinini and Panagaenini among others (Liebherr \& Will, 1998), all of which belong to the phyletic lineage of "modern" carabids (the Conchifera stock of Jeannel, 1941, or the Harpalidae of Deuve, 1988). This villous canal may be a general feature of this large lineage, as Ortuno described it in species of the tribes Chlaenini (1994) and Oodini (1998), and we have found it in species of the tribe Harpalini (data not shown). However, only in Zabrus does the villous canal end in a well developed falciform shaped head (perhaps of glandular nature), which appears to be another autapomorphy of the genus. The differentiation of the bursa copulatrix into two regions, a distal one that has either a simple tubular shape or from 1 to 12 cup-like infoldings and a basal that has a more or less inflated shape, is also remarkable. Schuler (1968) reported the extraordinary number of infoldings in the distal bursa of Zabrus (Pelor) obesus. Both regions of the bursa may serve to store sperm, although as Liebherr \& Will (1998) noted, the function of the various components of the female reproductive tract in Carabidae is unclear.

Gonocoxite 2 is variable in size, shape, and number and distribution of setae, both within and between the tribes of Carabidae (see for example Liebherr \& Will, 1998). It has not the strong and short spines that are found in species of Amara (although the presence of these spines varies within and between its subgenera), and in the related tribes Pterostichini, Platynini, and Sphodrini. 


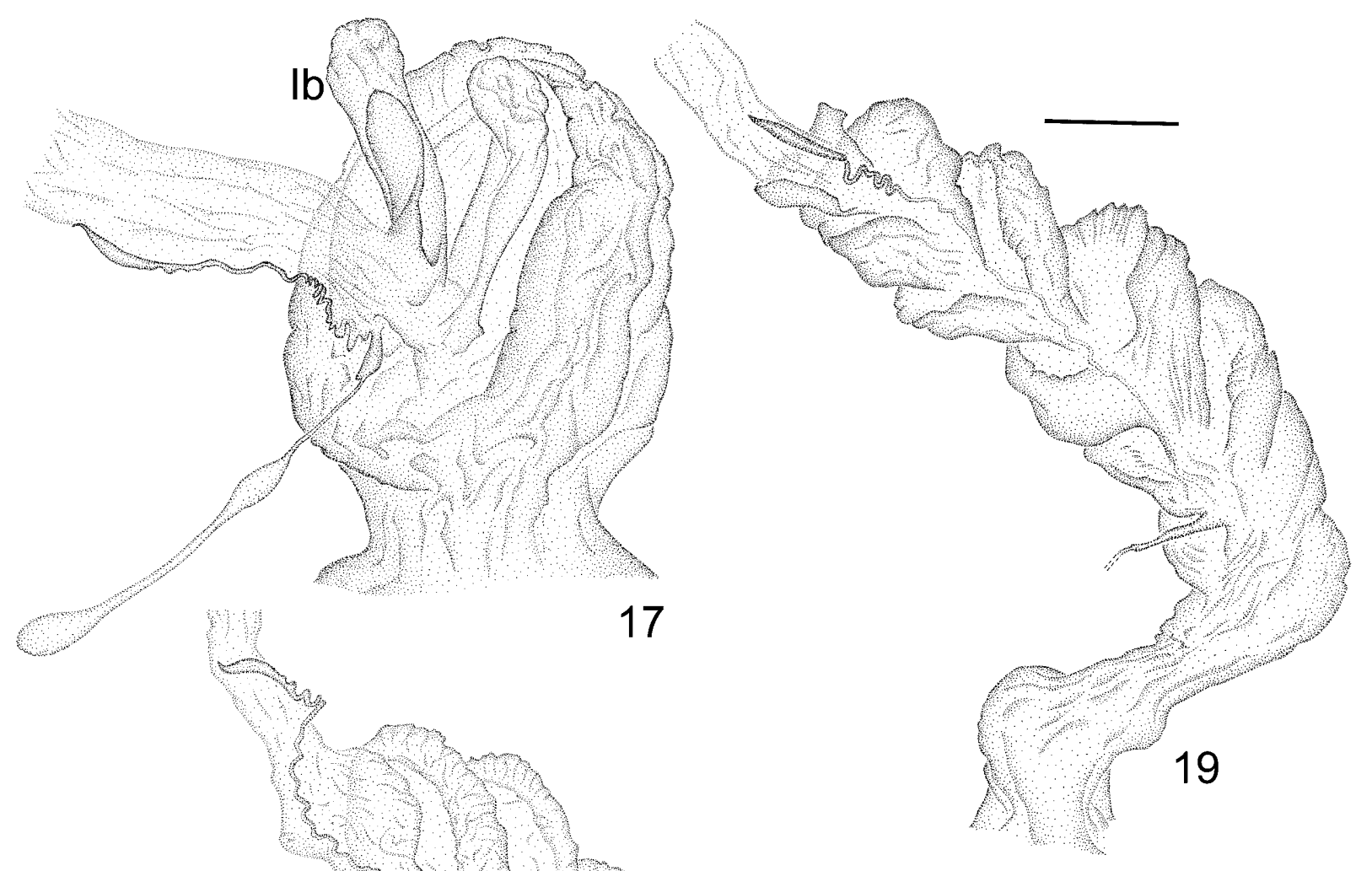

Figs 17-18. Female reproductive tract of selected species of the subgenus Iberozabrus $(17-Z$. seidlitzi; $18-Z$. coiffaiti). Note the extra lobules (lb) in the bursa of $Z$. seidlitzi. The bar equals $1 \mathrm{~mm}$.

Fig. 19. Female reproductive tract of Zabrus (Pelor) corpulentus. Note the many infoldings in the distal bursa.

\section{Variation in the general structure in the subgenera of Zabrus}

The structure of the female genitalia of the subgenus Zabrus is relatively simple, which accords with the primitiveness of the three species of the subgenus, which can fly, have a large distribution area, and are not limited to particular mountains (Andújar \& Serrano, 2001). The species of this subgenus are considered to be closely related to the ancestors of the genus (Andújar \& Serrano, 2001). The three species can be identified by the differences described above. The gonocoxites of the single species of the subgenus Euryzabrus, Z. pinguis, are unusually elongate and of about the same length, a character perhaps related to the preference of the species for sandy places on the NW coast of the Iberian Peninsula. On the other hand, the bursa is very simple. These features plus other morphological peculiarities described by Andújar \& Serrano (2001), indicate the phylogenetic isolation of Euryzabrus.

In the subgenus Platyzabrus gonocoxite 2 has a remarkably high number of setae. Both species of the subgenus, Z. constrictus (Sierra de Béjar) and Z. pecoudi (Sierra de Gredos), have a very similar female genitalia. Their overall similarity suggests they are a result of recent allopatric speciation in the mountains of the Sistema Central (middle Iberian Peninsula). Minor but consistent differences are found in the female genitalia of the three species of the subgenus Epomidozabrus. The most remarkable feature is the variously developed extra lobule where the two parts of the bursa meet. This feature plus the morphological apomorphies (particularly the thick basal margin of elytron and protruding humeral tooth) and its geographic distribution (NW of the Iberian Peninsula) indicate its monophyly.

These four subgenera have a simple distal tubular region of the bursa (only $Z$. tenebrioides has some vestigial infoldings), a character state that should be considered primitive compared to the complex pattern of infoldings found in other subgenera (Pelor, Iberozabrus). This ancestral character of this simple bursa does not support a close relationship between these four subgenera, which agrees with the conclusion of Andújar \& Serrano 
(2001) based on a cladistic analysis of the external morphology.

From this study it is concluded that the female reproductive tract of Zabrus is a valuable source of characters for the phylogenetic analysis of the genus. These include (at least) the length, shape and setation of the gonocoxites, the number of furrow pegs, the microtrichia on the articulating membrane between the gonocoxites, the development (infoldings) of the distal tubular bursa copulatrix, and the presence of extra lobules at the origin of the distal bursa. Further studies now in progress on all the subgenera and species of Zabrus will assess the phylogenetic value of these characters. It is expected that they, together with others based on external morphology, the sequence of cytochrome oxidase I (Sánchez-Gea et al., in prep.) and the karyotype data (Galián et al., 1991, and unpubl. data), will contribute to a better understanding of the phylogeny and evolution of this complex genus.

ACKNOWLEDGEMENTS. Thanks are due to the institutions and colleagues who generously loaned many specimens for the study. We also acknowledge the valuable suggestions and the linguistic revision of Prof. Martin L. Luff (Newcastle) and one anonymous reviewer. This work has been supported by the projects PB95-0235 and PB98-0402, both granted by the Dirección General de Enseñanza Superior e Investigación Cientifica of the Spanish Government.

\section{REFERENCES}

Aur H.A. 1967: The higher classification of the Carabidae and the significance of internal characters (Coleoptera). Bull. Soc. Entomol. d'Egypt 51: 211-231.

AndúJar A. \& SERrano J. 2000: Taxonomic notes on the genus Zabrus (Coleoptera: Carabidae: Zabrini). Bol. Asoc. Españ. Entomol. 24: 185-193.

ANDÚJAR A. \& SERRANo J. 2001: Revisión y filogenia de los Zabrus Clairville, 1806 de la península Ibérica (Coleoptera: Carabidae). Monografias de la Sociedad Aragonesa de Entomología, No. 5. Zaragoza, $90 \mathrm{pp}$.

Deuve T. 1988: Étude phylogénétique des Coléoptères Adephaga: redéfinition de la famille des Harpalidae, sensu novo, et position systématique des Pseudomorphinae et Brachinidae. Bull. Soc. Entomol. Fr. 92: 161-182.

FREUdE H. 1986: Revision der zur (?) Gattung "Zabrus" Clairville, 1806 gehörenden Arten mit Bestimmungstabellen (Col.: Carabidae). Atti Mus. Civ. Stor. Natur. Trieste 39: 133-150.
Freude H. 1988: Revision der zur (?) Gattung “Zabrus" Clairville, 1806 gehörenden Arten mit Bestimmungstabellen (Col.: Carabidae). 2. Teil. Atti Mus. Civ. Stor. Natur. Trieste 41: 133-142.

Freude H. 1989: Revision der zur (?) Gattung "Zabrus" Clairville, 1806 gehörenden Arten mit Bestimmungstabellen (Col.: Carabidae). 3. Teil. Atti Mus. Civ. Stor. Natur. Trieste 42: 71-153.

FreUde H. 1990: Revision der zur (?) Gattung "Zabrus" Clairville 1806 gehörenden Arten mit Bestimmungstabellen (Col.: Carabidae). 4. Atti Mus. Civ. Stor. Natur. Trieste 43: 329-364.

Galián J., Ortiz A.S. \& Serrano J. 1991: Amara and Zabrus, two different patterns of karyotypic evolution (Coleoptera: Carabidae). Caryologia 44: 75-84.

Ganglbauer L. 1915: Revision der Gattung Zabrus Clairv. Münch. Koleopter. Zeitsch. 4: 87-137.

HoldHaus K. 1912: Monographie der paläarktischen Arten der Coleopterengattung Microlestes. Denkschr. Mat.-Naturw. Klasse Kaiser. Akad. Wiss., Wien 88: 477-540.

Jeannel R. 1941: Coléoptères Carabiques. Faune de France 39. 1ème partie. Lechevalier, Paris, 571 pp.

LiebHerR J.K. 1989a: Review of the Palearctic genus Paranchodemus Habu (Coleoptera: Carabidae: Platynini). Pan-Pacific Entomol. 65: 1-11.

LIEBHERR J.K. 1989b: Tanystoma diabolica new species (Coleoptera: Carabidae: Platynini) from Baja California and its biogeographic significance. J. N. Y. Entomol. Soc. 97: 173-186.

LIEBHERR J.K. \& WiLL K.W. 1998: Inferring phylogenetic relationships within Carabidae (Insecta: Coleoptera) from characters of the female reproductive tract. In: Ball G.E., Casale A. \& Vigna Taglianti A. (eds): Phylogeny and Classification of Caraboidea (Coleoptera: Adephaga). Museo Regionale Scienze Naturali, Torino, pp 107-170.

ORTuÑo V.M. 1994: Estudio de la genitalia femenina en las especies ibéricas de Trichochlaenius Seidlitz, 1827 (Col.: Caraboidea, Callistidae). Bol. Soc. Portug. Entomol. Supl. 3: $51-59$.

ORTuÑo V.M. 1998: La genitalia femenina en los Oodinae (Caraboidea: Callistidae) de la región Paleártica Occidental. Elytron 12: 3-10.

Ortuño V.M., Outerelo R. \& Alonso J. 1992: Estudio taxonómico comparativo de las especies ibéricas de Chlaeniellus Reitter, 1908 (Coleoptera: Caraboidea, Callistidae). Bol. Real Soc.Españ. Hist. Natur. (Sec. Biol.) 88: 147-163.

SCHULER L. 1968: Les organes genitaux fémelles chez les Zabrinae de France (Col: Pterostichidae). Bull. Soc. Entomol. Mulhause, mars-avril: 17-26.

Received May 23, 2002; revised September 3, 2002; accepted November 20, 2002 